\title{
Biography resources
}

\section{Finding information on the famous, infamous, and obscure}

\author{
by Susan A. Schreiner and Michael A. Somers
}

$\mathbf{F}$ inding biographical information on the Internet is both time-consuming and frustrating. While any particular name can retrieve a number of hits on any search engine of your choice, finding current, accurate biographies can be difficult. Fortunately, the Internet is a rich source of diverse biographical information, and the following sites will guide users to an array of information on numerous topics. This collection is by no means comprehensive (what guide on the Internet is?), but the sites were chosen for the depth of their articles or the sheer bulk of biographical materials available.

\section{Biographical search engines}

- Freeality. The site offers users a variety of sources for searching online biographies. There are links to both general and specific resources, such as "Information Please" and "First Ladies." There is also a section labeled "Famous People" with links to ten additional resources, which run the gamut from "Women in Science" to "Billionaires" to "Popes." Each resource contains both a link to the resource itself and a search box that searches that particular site. It is an easy-to-use site with many navigational links and eye-catching graphics. While this site does not attempt to be exhaustive, it is a good first stop. Access: http://www.freeality.com/biograph.htm.
- Yahoo: People. Has anyone on this planet not used Yahoo? The organization of the site is Yahoo's hallmark. There is a general list of categories followed by site listings. The categories are useful, but the extent of the links is inconsistent. Access: http://dir.yahoo.com/Society_and_Culture/ People/.

\section{General biography}

- Biography.com. Created by the A\&E network and based on the popular show Biography, this site offers basic biographical information on more than 25,000 famous and notable persons. Although popular figures and historical names tend to have much more indepth biographies than important scholars and obscure names, this is an excellent starting point for anyone searching for biographical information. Access: http://biography.com/.

- Biographical Dictionary. Offering information on more than 28,000 persons, this site is another good starting point for bio-

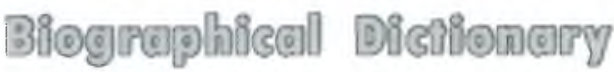

graphical research. Usually presenting good and somewhat in-depth preliminary information on historical figures, this site tends to be weaker on current biography. While sometimes providing more information than

\section{About the authors}

Susan A. Schreiner is pursuing a second master's degree, e-mail: libschr@isugwindstate.edu; and Michael A. Somers is assistant dean for library services at Indiana State University, e-mail: isugw.indstate.edu 
Biography.com, it is presented in a less readable fashion. Overall, this is a good site that will help students find basic information, especially on historical figures. Access: http:// www.s9.com/biography/.

- Distinguished Women of Past and Present. Created and maintained by Danuta Bois, this site links to numerous biographies of "women who contributed to our culture in many different ways ... [including] . . . educators, scientists, heads of state, politicians, civil rights crusaders, artists, entertainers, and others." Although many of the links tested are no longer available and the collection of names is still limited, the biographies reviewed are well-written and the links informative. $A C$ cess: http://www distinguishedwomen.com/.

\section{Artistic lives}

- the-artists.org. The splash page for this site is deceptively simple. There are two primary search options - biographies of 20th century and contemporary visual artists from an alphabetical list or artist's name from a list organized by art movement, style, or medium. Although the biographical data is brief, each contains a picture of the artist and each has links to additional sites and resources. Access: http://www.the-artists.org/.

- Union List of Artist Names (ULAN). ULAN is, according to its help screens, a structured vocabulary "that contains around 220,000 names and other information about artists." The scope is global and the periods covered are from antiquity to the present. Each record includes variations of the artist's name, dates, geographic locations, relationships (such as student-teacher relationships), notes, and sources for the data. Records can be purchased and downloaded so that an institution can create its own database with this information. Access: http://www.getty.edu/ research/tools/vocabulary/ulan/.

- Artists' Biographies. This is one of the most comprehensive sites for information about painters, sculptors, photographers, architects, designers, and other artists. Of the more than 16,000 biographies listed, some 15,000 are derived from articles in The Grove Dictionary of Art. All of the articles on this site are free and available to users. Since the additional links on most pages are to the online version of the dictionary itself, the user may be thwarted if the user or the library does not have a sub- scription. Access: http://www.artnet.com/ library/index.asp.

\section{Hollywood lives}

- Internet Movie Database (IMDb). IMDb (Access: htp://www.imdb.com/) allows searching of anyone involved with filmmaking. $\mathrm{Al}$ though this site provides good information on a variety of different Hollywood types, the search engine brings up many trivial hits. A better choice is to go directly to the alphabetical biographies index at http://us.imdb.com/ Sections/Biographies/Index/A.

- What a Character!.com. Providing biographical information on hundreds of character actors, this site allows searching by an alphabetical index that also includes each actor's photograph. Great fun to search as you learn more about many actors you know only by sight. The site provides a brief bio and complete filmography of the film and television appearances of each actor. Access: http:// www.what-a-character.com/.

\section{Legal lives}

- Supreme Court Justices. This site offers comprehensive biographical information on every Supreme Court justice from John Jay to Stephen Breyer. It includes details on each justice's personal life, education, legal career and case participation, as well as his or her predecessor and successor. A very welldone site. Access: http://oyez.nwu.edu/ justices/justices.cgi.

- Women's Legal History Biography Project. Developed for a Stanford course on Women's Legal History, these biographies on women in the field of law were written by students. Due to difficulties in maintaining current information on living women, the site now plans to add only posthumous biographies in the future. Although limited in subject and number of women studied, the articles are comprehensive and well written. Access: http://www.stanford.edu/group/WLHP/.

\section{Literary lives}

- Book Lovers-Great Writers. This personal page is wonderfully eccentric. The owner clearly states that the writers listed have achieved "world literature level" and that they have at least one "significant" Web page devoted to them. Although some of the links are no longer active, the majority are and they lead 
to some intriguing, informative sites. By no means a comprehensive site, some of the links are unique and beneficial. Access: http:// www.xstall.nl/ pwessel/writers.html.

- Voices From the Gaps: Women Writers of Color. Hosted by the University of Minnesota, this instructional site focuses on the lives and works of North American women writers of color. Writers can be located either by name, birthplace or geographical location, racial/ethnic background, or significant dates. Not all of the writers listed have completed biographies. However, the ones available are very well crafted and include bibliographies and related links. A very valuable tool for students and scholars alike. Access: http:// voices.cla.umn.edu/.

- Biographies: The Poets. A general utility site, the descriptions of the poets' lives and works are usually succinct. The list of poets is rather brief and biased toward British writers from the 17th through the 19th centuries. What is intriguing about this site are the eccentric related links, which range from more complete biographies of the poets themselves to individual poems to other biographies in different sections of the site itself. Access: http:// www.blupete.com/Literature/Biographies/Literary/BiosPoets.htm.

\section{Military lives}

- History Makers. This site contains two related pages: Confederate Generals of the Civil War (Access: http://www.historycentral. $\mathrm{com} / \mathrm{bio} / \mathrm{CW}$ cGENS/index.h(ml) and Union Generals of the Civil War (Access: http:// Www.historycentral.com/bio/UGENS/ Index.html). Accessed from the historycentral. com splash page directly or via the "History Makers" page, the biographies are listed alphabetically. Each general's page includes an image of some type, vital statistics (including highest rank achieved), and an extensive biography. This is a useful tool for the casual learner. Access: http://www.historycentral. $\mathrm{com} / \mathrm{bio} /$ index.html.

- WWI Biographical Dictionary. Prominently displayed on each page of this site is a disclaimer that the site is incomplete and under construction. However, the site does contain valuable descriptions of some of the major world figures from this era. The biographies vary from the succinct to the more extensive and each includes an image. As an educational site, its value will improve as more biographies are added. Access: http://raven.cc.ukans.edu/ 〜kansite/ww_one/bio/bios-home.html.

\section{Musical lives}

Finding information on famous musicians is made easier by several sites.

- Classical composers are presented both on the Naxos site, provided by HNH International Ltd. (Access: http://www.naxos.com/ newDesign/fcomposers,files/bcomposers.htm), and at Dr. Estrella's Incredibly Abridged Dictionary of Classical Composers. Access: http://www stevenestrella.com/composers/ index.html.

- Rock and Roll Hall of Fame. Information on rock stars inducted into the Rock and Roll Hall of Fame can be searched by name or induction year at this site. Access: http:// www.rockhall.com/hof/allinductees.asp?sort= $\ln \% 2 \mathrm{Cfn}$.

- PBS Jazz. Nearly 100 famous jazz musicians are profiled at this site; audio samples of the artists' work are included. Access: http://www pbs. org/jazz/biography/.

- All-Media Guide. This site provides information on all types of musicians, with biographical details presented in six languages, information on recordings, tours and history, listings and links to major influences, and a summary of the artisc's/group's achievements. Access: http://www.allmusic.com/.

\section{Philosophical lives}

- Major World Philosophers. For basic information about the major philosophers of the world, this site provides concise descriptions of the philosopher's origins, major field of philosophical investigation, and bits of other pertinent information, which helps identify the accomplishments and achievements of each philosopher. For those just learning about philosophy, this is a beneficial site. Access: http://www.cftech.com/Brain Bank/ OTHERREFERENCE/PHILOSOPHY/ MajWrldPhilsop.html.

- Stanford Encyclopedia of Philosophy. A dynamic reference tool, the entries are written and maintained by experts in the field, who update them as needed. All entries, whether new or updated, are rigorously reviewed by the editorial board before they are loaded onto the site. The biographical entries are richly detailed, containing lengthy explanations of the 
philosopher's areas of inquiry, bibliographies, and links to related sites. By no means complete, the encyclopedia is impressive, even in its current abridged form. Access: http:// plato.stanford.edu/.

\section{Political lives}

American politics are always a favorite research topic. Fortunately several good sites offer indepth information on our national leaders.

- Both American Presidents, developed by C-Span (Access: http://Www. americanpresidents.org/22.asp), and POTUS: Presidents of the United States, an Internet Public Library site (Access: http:// www.potus.com/), offer detailed information on all 43 U.S. Presidents, including film and

\section{(0) POTUS}

\section{Presidents of the United States}

audio clips, transcripts of speeches, and further research information.

- First Ladies of the USA. This site presents each First Ladies' history in an interesting, easy-to-read manner. Access: http:// www.whitehouse.gov/history/firstladies/.

- Biographical Directory of the United States Congress. Interested in learning more about your favorite senator? Try this site, which offers a brief summary of the historical high-

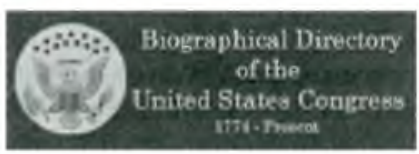
the members of Congress from 1774 on. Access: http://bioguide.congress.gov/ biosearch/biosearch.asp.

- The Political Graveyard. Finally, although professing to be "The Web site that tells where the dead politicians are buried," the Political Graveyard also provides basic biographical information on tens of thousands of politicians, including dates of birth and death (if applicable), political position held, relationship to other political figures, and numerous links to other pertinent information. Access: http://potifos.com/tpg/.

\section{Scientific lives}

- 4000 Years of Women in Science. This unique site offers browsers a glimpse into the lights of

lives of an impressive handful of women scientists. Arranged alphabetically, the list can also be sorted by field of study or time period. Each biography is too brief, since the discoveries and accomplishments are certainly notable. A good starting point to pique one's curiosity. Access: http://www.astr.ua.edu/4000Ws/ summary shtml.

- African-Americans in the Sciences. As an information resource, this site excels at both the depth of the information provided and the ease of navigating through it. A great compilation of African American scientists and engineers, the men and women featured on this page have achieved success in mathematics, chemistry, physics, meteorology, and zoology, as well as other related sciences. Certainly, this is a worthwhile educational site. Access: http://www.princeton.edu/ mcbrown/ display/faces.html.

- Mathematicians. A great resource, this site is updated regularly and provides the depth of information to ensure its educational utility. The site is comprehensive and well organized with universal scope and detailed biographies. Most biographies include a portrait, a list of references, a link to other mathematicians born in the same country, and other useful links. This educational site is a reference librarian's best friend for information in this subject area. Access: http://wow-groups.dcs.st-and.ac.uk/ $\sim$ history/BiogIndex.html.

- National Inventors. Sponsored by the National Inventors Hall of Fame, the biographies listed on this site range from the brief to the detailed. Each inventor is an inductee into the Hall of Fame and each biography lists the date of induction, the notable invention(s), and the patent number(s). The biographies are informative with links to additional sites. Access: http://www.invent.org/book/book-text/ indexbyname.html.

- Biographies of Biologists. A BIOSIS resource guide, the entries listed are selectively culled from other online sites and organized alphabetically. This is not an exhaustive list, but it is impressive and easy to use. For those who need quick access to information about biologists, this is a good starting point. Access: http://www biosis.org/zrdocs/zoolinfo/ biograph.htm.

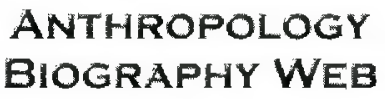

- Anthropology Biogra-

phy Web. This site was (continued on page 39) 
and Rare Books cataloger, Stanford University Libraries, Catalog Department.

\section{University Libraries Section}

Vice-chair/Chair-elect: Bruce Henson, acting head, Reference Department and reference librarian, Georgia Institute of Technology; Gillian McCombs, Central University librarian, Southern Methodist University.

Member-at-large: Najit Brar, assistant dean, Access and Bibliographic Services, and Library Systems, California Polytechnic State University; Lynn S. Cline, head, Collection Development and Acquisitions, Southwest Missouri State University Libraries; Frank Mols, assistant director for Technical Services, State University of New York at Binghamton, Libraries; Peter Watson-Boone, library director, University of Wisconsin, Milwaukee.

\section{Western European Studies Section}

Vice-chair/Chair-elect: Katalin Radics, WestEuropean bibliographer, Charles E. Young Research Library, University of California Los Angeles; Ann P. Snoeyenbos, librarian for West European Social Science, New York University. Secretary: Candace $Y$. Miller, reference libratian, James Madison University; Louts Reith, rare book cataloger, Georgetown University. Member-at-large: Laura Dale Bischof, librarian for Western European History and Social Sciences, University of Minnesota; Bryan Skib, coordinator of Graduate Library Collections, University of Michigan.

\section{Women's Studies Section}

Vice-chair/Chair-elect: Laura Micham, head of Public Services, Special Collections and Archives Division, Emory University; Sandra A. River, current periodicals/microforms librarian with dual appointment in Information Services (liaison to English, Philosophy, and Women's Studies).

Secretary: Cyntbia A. Johnson, reference and collection development, Barnard College; Martha Henn McCormick, Women's Studies and English librarian and program director, Information Resources Unit of the Center for Teaching and Learning, University Library of Indiana University Purdue University Indianapolis.

Member-at-large: Jennifer $R$. Gilley, assistant librarian, Penn State New Kensington; Kelly $B$. Hovendick, reference librarian, Sociology and Women's Studies Specialist, Syracuse University, E. S. Bird Library.
"Becoming part of the course" cont. from page 13)

\section{External Links}

The External Links area is used to reference Web sites related to a course. Use this area to showcase a list of evaluated electronic reference materials that you have discovered. You can also use External Links in conjunction with the Discussion Board. Have students send the URL of one Web site on their research topic to the Discussion Board and then post all the sites to the External Links page. Have students evaluate the Web sites and discuss whether they would be worthy of citation in their final bibliographies.

As you can see, Blackboard and similar courseware packages offer librarians an op- portunity to participate more fully in the coursework of our university's students. Even if a one-hour session is all the class time a faculty member is willing to give us, we can be active members of a course, answering questions, participating in discussions, directing students in the successful completion of their research.

\section{Notes}

1. WPI currently uses Blackboard 5.5 Level 3. For more information, see Blackboard's Web site at http://www.blackboard.com.

2. Nancy K. Getty, Barbara Burd, Sarah K. Burns, and Linda Piele. "Using Courseware to Deliver Library Instruction via the Web: Four Examples," Reference Services Review 28 No. 4 (2000): 349-59
("Biography resources" cont. from page 35) developed by students in the anthropology program at the University of Minnesota, Mankato, as part of an e-museum. The site is "by no means a comprehensive list," but more names are added each semester. The list, arranged alphabetically, contains almost 500 names of people who have influenced anthropology. A very useful tool that is easy to navigate. Access: http:// emuseum.mnsu.edu/information/biography/. 